\title{
Critical gradients for tailings dam design
}

\author{
I. Jantzer Luleå University of Technology, Sweden \\ S. Knutsson Luleå University of Technology, Sweden
}

\begin{abstract}
Knowledge on tailings dams design is often derived from conventional earth and rock fill dams that are designed for relatively short service periods. Tailings dams often differ in both structural design and service life, where a long term stability of 1,000 years or more is demanded. One of the most important factors related to tailings dams stability and performance in long term perspective is the prevention of failure from internal erosion, i.e. particle migration initiated by seepage pressure.

Internal erosion is a process not yet completely understood; it is related to the seepage rate, which in turn connected to the hydraulic gradient, internal structure, particle size distribution etc. The hydraulic gradient is therefore crucial for embankment stability and prevention of particle migration for a given material. A basic research question is: Does a maximum hydraulic gradient in a given material exist, below which internal erosion cannot be initiated? If so, what maximum gradient can we allow for a tailings dam construction in order to prevent internal erosion with respect to the long term stability of the construction?

The maximum, or critical, gradient is often related to slope stability problems, heave, or blow out. Such critical values differ from a critical hydraulic gradient for internal erosion problems taking place inside the soil matrix. To be able to apply critical values on internal erosion problems, clear definitions and information on the origin of a given critical hydraulic gradient is needed. This paper presents a detailed literature survey on reported values of critical hydraulic gradients for the initiation of piping. These values are derived from laboratory tests and from experiences of conventional dam constructions, i.e. they have to be looked upon in a limited time perspective. The paper discusses the use of these values for tailings dams design.

To take the long term aspect into account, natural analogies to dam constructions have been analysed. These structures are formations from the last glaciations that have fulfilled the task of damming water. Such structures are especially interesting with regard to their obvious stability against internal erosion over long time periods. Natural analogies to dam constructions in Sweden are analysed to some extent and presented in the paper. Results show that they are stable under a hydraulic gradient between 0.02 and 0.05 . Current guidelines on tailings dam design in Sweden allow a hydraulic gradient where neither the long term stability of the construction nor the possible degradation of the construction material is taken into account. To ensure a long term stability of tailings dam constructions, a more thorough understanding of the critical hydraulic gradient is needed, and a modification of the present design guidelines is suggested.
\end{abstract}

\section{Introduction}

The increasing demand of metals and minerals has made it economical to mine low-grade deposits, which in turn results in immense quantities of waste material. In fact, mine wastes are the largest waste volumes produced on earth (Mitchell and Soga, 2005; Bjelkevik, 2005a). These waste volumes comprise fine grained particles with varying characteristics dependent on the origin of the ore and different extraction processes. The physiochemical nature of the original natural material is altered; the particles have an increased and chemically treated surface after processing. A major concern is therefore to minimise the environmental impact from tailings, i.e. the release of metals or trace elements, due to oxidation and weathering, or the release of acidic water due to leakage from the pond.

Tailings deposits must be stable over long time periods of 'thousands of years' without maintenance. However, they will experience degradation and decay after the mining site is abandoned. One possible cause for degradation is internal erosion, a problem which has been responsible for accidents and failures of dam constructions all over the world. Wherever water is dammed by an embankment of soil, gravel, and rock, the 
particles are exposed to a hydraulic gradient, imposing a seepage force through which particles in the soil skeleton may start to move and migrate through an unprotected exit in the soil structure, eventually leading to leakage through the embankment. An overall failure statistic carried out by Foster et al. (2000) showed that $30.5 \%$ of failures of large embankments, i.e. water retention dams, were due to internal erosion through the embankment. Davies (2002) states that piping is the main failure mode for non-upstream tailings dams, i.e. internal erosion. Incidents at Swedish tailings dams were analysed by Bjelkevik (2005b), who found that $19 \%$ of the reported events were related to internal erosion.

Various expressions are used when speaking about internal erosion. It is often referred to piping, which implies that a continuous open seepage path grows, i.e. a 'pipe', through which particles are carried away. Backward erosion describes a process where material starts to erode at a free and unfiltered exit of the seepage path, continuing backwards towards the upstream face of the dam, see Figure 1a. In contrast to that, concentrated leakage erosion starts in the dam body and progresses outward, see Figure $1 \mathrm{~b}$, a process that may result from, e.g. poor compaction, differential settlements, frost action, etc. (Fell et al., 2005).

a)

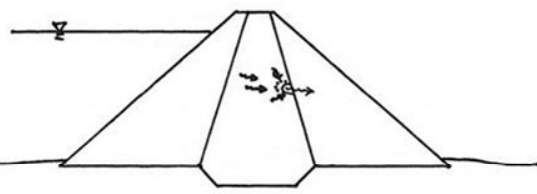

b)

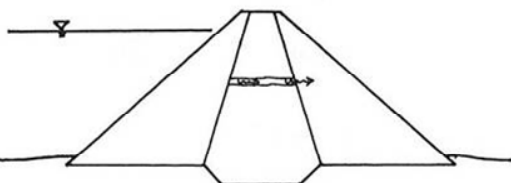

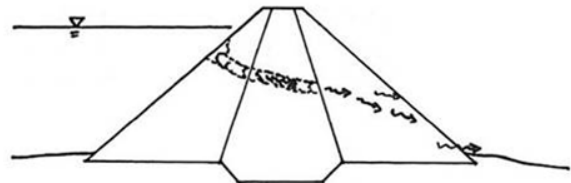

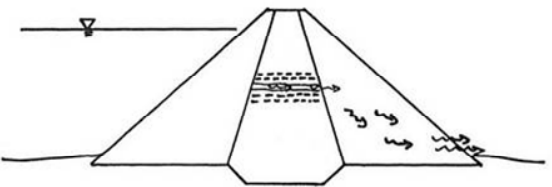

Figure 1 Backward erosion (a) and concentrated leak (b) (Fell et al., 2005)

A number of studies on criteria for internal erosion have been conducted, including studies on the critical hydraulic gradients to avoid erosion for different soil materials. However, laboratory testing can only give information on a material's behaviour in limited time perspective. Therefore, information from long term stable natural analogies to dam structures is taken into account. Many stable natural dammed lakes dating back to the most recent melting of continental ice in Sweden about 15,000 to 8,000 years ago can still be found today. Examples of such natural dammed lakes are presented and analysed with respect to the hydraulic gradient the soil is exposed to. Research questions are: What hydraulic gradient can a natural analogy to a dam construction withstand over thousands of years? Does a maximum hydraulic gradient exist in a given material with respect to internal erosion? Based on such examples, what maximum gradient can we allow for a tailings dam construction with regard to its long term stability and internal erosion? A literature study on critical hydraulic gradients, as well as studies on natural analogies, was conducted. Results are summarised and compared to current tailings dam design practice in Sweden.

\section{Criteria for internal erosion}

\subsection{Geometric and hydraulic criteria}

Studies on internal erosion originally focused on mechanical principles, i.e. geometric criteria, where primarily particle and opening sizes in the soil matrix allowing particle movement were investigated. Many geometric considerations are still based on Terzaghi's filter criteria from the early 1920s, where the relation between a filter material (index $\mathrm{f}$ ) for a base soil (index b) is defined: (1) for erosion control, the relation between filter and base soil should be $d_{15 f} / d_{85 b} \leq 4$, and (2) to guarantee drainage the relation should become $\mathrm{d}_{15 f} / \mathrm{d}_{15 \mathrm{~b}} \geq 4$. The index denotes the grain size for which 15 or $85 \%$ is finer, respectively (Terzaghi et al., 1996). 
These relations have been discussed by many researchers, among them Sherard et al. (1984), Lafleur (1984), Kenney and Lau (1985), Lafleur et al. (1989), and Chapuis (1992). Despite all studies and filter testing, the concept of retaining particles and ensuring of drainage is still in use. Moreover, Sherard et al. (1984) stated that Terzaghis criteria "employ the appropriate characteristics of the filter and the base", so that the ratio "should be continued as the main criterion for judging filter acceptability". Recent laboratory studies carried out by Fannin and Moffat (2006) also approved the concept introduced by Terzaghi.

Filter criteria were developed with respect to the interaction of a filter with a base soil, i.e. two adjacent soils. The self-filtration problem, i.e. internal instability in one soil material, was regarded by Kenney and Lau (1985), who divided the soil into two units, a primary fabric which transfers load and stress, and loose particles in the voids of the primary fabric. If a material is internally unstable it lacks the capacity of selffiltration, and loose particles can migrate through the skeleton of coarser particles. Such materials experience the washout of grains at lower hydraulic gradients than stable materials (Skempton and Brogan, 1994).

Hence, hydraulic criteria for internal erosion are directly connected to the geometric conditions in the fabric. Hydraulic criteria summarise the boundary conditions for hydraulic loads acting on a soil particle and forcing it to move. Even if the soils structure geometrically allows an opening size in the pore matrix large enough for displacement, a hydraulic load exceeding the drag force, i.e. the particles' self-weight and its interaction with other grains is needed to actually move a particle. Both mechanisms are responsible for stability against particle transport: particle geometry, and sufficiently low hydraulic forces (den Adel et al., 1988).

In the following section, the definition of critical hydraulic gradient is discussed. Various laboratory test procedures developed to investigate erosion potential are compared. Values for critical hydraulic gradients have been summarised by Perzlmaier et al. (2007). Other limit values introduced by Skempton and Brogan (1994), Tomlinson and Vaid (2000), den Adel et al. (1988) and Richards and Reddy (2009) are presented.

\section{2}

\section{Critical hydraulic gradients}

\subsection{1}

\section{Definition}

Terzaghi et al. (1996) defined the hydraulic gradient for upward directed flow that reduces the effective stress to zero to be the critical hydraulic gradient $i_{c}$. The critical hydraulic gradient is thus dependent on the porosity $n$ of the material and its bulk density, or the bulk density $\rho$ and the density of water $\rho_{\underline{w}}$ :

$$
i_{c}=(1-n)(1-\rho)=\frac{\rho-\rho_{w}}{\rho_{w}}
$$

Using this definition, the critical hydraulic gradient is equal to 1 . This condition is described as heave, blowout, quick-condition, liquefaction, boiling of sand etc.

Critical hydraulic gradients related to internal erosion are often significantly lower than that suggested by Equation (1). For instance, Wan and Fell (2004b) define the critical hydraulic gradient as given by Terzaghi, but introduce an initiating hydraulic gradient $i_{\text {start }}$, at which erosion of particles starts, and a hydraulic gradient at boiling $i_{\text {boil }}$, which is the minimum hydraulic gradient to observe boiling at the surface of a test specimen. Other authors are not as detailed in their definition, but define the hydraulic gradient which initiates particle movement or piping as critical gradient $\mathrm{i}_{\mathrm{q}}$ (e.g. Zhang and Chen, 2006; Richards and Reddy, 2009; Skempton and Brogan, 1994). The critical hydraulic gradient can also be defined by the rate at which washing out occurs, which has been done by den Adel et al. (1988). This approach includes that the amount of eroded material needs to be quantified, i.e. the amount of washed-out material in the outflow has to be measured.

It appears that there is an agreement about the critical hydraulic gradient being that at which particles start to move, which is lower than Terzaghis theory predicts. However, there is no clear limit regarding the rate of particle migration to define an exact boundary value.

\subsubsection{Laboratory testing on internal erosion}

Over the years, a number of different laboratory methods have been developed in order to test and classify soils according to their susceptibility for piping and erosion, e.g. the pinhole test, the jet erosion test, flume 
tests and the rotation cylinder test. These tests have been presented and summarised by various authors, e.g. Sherard et al. (1976), Wan and Fell (2004a) and Richards and Reddy (2009). More recent laboratory studies are described below. It should be noted that the determined critical gradients are results from tests in different directions, i.e. horizontal, or vertical up or downward. Both Richards and Reddy (2009) and Saucke (2006) state that the direction in relation to gravity has a significant influence on material transport.

Experimental studies on the interaction of a filter-base soil system with respect to filter thickness, confining pressure, hydraulic gradient, as well as rate of gradient increase upon piping were carried out by Tomlinson and Vaid (2000). The permeameter allows the independent control of above named variables, and samples are tested with a filter layer made of glass beads in order to eliminate the influence of inhomogeneities in natural materials. These tests are unique in that they are carried out vertically downward, so that "gravity assists the soil grains to migrate and highlights the potential for erosion” (Tomlinson and Vaid, 2000).

Wan and Fell (2004a) introduced both the hole erosion test (HET) and the slot erosion test (SET) in order to investigate the erosion characteristics, i.e. the erosion rate index and a critical erosion shear stress at which erosion starts. Similar to the pinhole test, samples are provided with artificial cracks prior to testing to simulate cracks and concentrated leaks in embankment dams. In the HET, the sample is compacted in a standard mold and a hole is drilled along the samples longitudinal axis. This implies that the soil sample should be cohesive to ensure that the drilled hole is kept open. In the SET, a soil sample is compacted in a $1 \mathrm{~m}$ long rigid box, and a slot is formed on the surface of the sample. The sample is then provided with a transparent cover through which erosion can be observed. In this case, both cohesive and non-cohesive samples may probably be used, but the testing procedure appears to be suitable to test the risk for internal erosion along rigid walls, such as conduits etc. Both SET and HET are considered to provide information on the potential for internal erosion (i.e. piping), but not on backward erosion. Both tests are carried out horizontally. In the HET, the diameter of the preformed crack is indirectly measured by the flow rate. In the SET, the increase in the width of the slot, i.e. the erosion, is measured over time.

Additional tests on the internal stability of soils were also carried out by Wan and Fell (2004b): the downward flow seepage test (DF) to investigate the internal stability of a soil, and the upward flow seepage test (UF) to test the hydraulic gradient at which internal erosion occurs. Both tests were carried out on intact samples, i.e. without cracks. In the DF test, the grain size distribution of the sample after testing is compared to the initial distribution to analyse whether suffusion has taken place. During the UF test, the change in flow rate and hydraulic gradient is measured and related to the rate of erosion which is indicated by the rate of washout of particles. For observation of the washout of particles, the top of the cell is left open.

Richards and Reddy (2009) presented the True Triaxial Piping Test Apparatus (TTPTA) to determine the critical hydraulic gradient at which piping occurs. The test is supposed to be suitable for non-cohesive materials. In addition to the critical gradient, the initiating critical velocity can be studied, which is considered to give more detailed and valuable information on piping initiation than the gradient. The TTPTA also enables the study of seepage direction in relation to the direction of gravity, thus verifying that horizontal or vertically upward directed tests cannot directly be compared due to the significant influence of gravity.

\subsubsection{Overview on limit values}

In case of internal erosion at the interface between a base and a filter material, the basic idea for the critical | gradient is related to the equation for heave, see equation (1). However, the critical hydraulic gradient is reduced by a factor of 0.7 to 0.8 (Ziems, 1969):

$$
i_{c}=\{0.7 \text { to } 0.8\} \frac{\rho-\rho_{w}}{\rho_{w}}
$$

Regarding a loaded condition, i.e. erosion at the interface between base and filter inside the soil matrix, | Ziems (1969) suggests an approximation of the critical gradient $i_{\mathrm{G}}$ valid for base materials with $\mathrm{C}_{\mathrm{u}, \mathrm{b}} \leq 5$ :

।

$$
i_{c} \approx 0.66 \frac{6}{d_{10 b}^{2} \cdot A_{50}^{2}}
$$

Formaterat: Teckensnitt:Kursiv

Borttaget: ${ }_{\text {rit }}$ 
Equation (3) is supposed to result in higher values of the critical gradient than Equation (2) (Ziems, 1969). It takes geometric conditions into account by relating both base (index $b$ ) and filter material (index $f$ ) to each other, introducing a 'distance-relationship' $A_{50}$ :

$$
A_{50}=\frac{d_{f, 50}}{d_{b, 50}}
$$

| To satisfy a recommended safety factor of 1.5 , the present value for $A_{50}$ should be compared to an admissible value, for which criteria can be found in (Saucke, 2006). The above given relationships presume that Darcy's law is valid even when reaching a critical velocity $v_{G}$

Criteria for suffusion, i.e. the selective transportation and washing out of fines from the coarser soil matrix, have also been published by Perzlmaier et al. (2007). The critical hydraulic gradient $i_{G}$ is considered to be dependent on the coefficient of uniformity ${ }_{4} C_{u}$, i.e. the risk for suffusion increases with increasing $C_{u}$ (Saucke, 2006), so that $\mathrm{i}_{\mathrm{G}}$ should be reduced:

$$
i_{c}=\left\{\begin{array}{cc}
0.3 \text { to } 0.4 & \text { for } C_{u}<10 \\
0.2 \text { for } & 10 \leq C_{u} \leq 20 \\
0.1 & \text { for } C_{u}>20
\end{array}\right\}
$$

An overview on critical hydraulic gradients based on empirical studies was presented by Perzlmaier et al (2007). The summary of hydraulic criteria for both backward erosion and piping, with average gradients divided into groups according to the grain size distribution of the soil, is shown in Table 1.

Both Bligh's and Lane's method (introduced as early as 1912 and 1934, respectively) do not refer to embankment dams, but to concrete barrages with a certain length of an apron and cut off to increase the seepage length (Mansour, 2005). Empirically obtained coefficients to relate seepage length and hydraulic head are based on experiences and performance of a number of such barrages. In contrast to Bligh, Lane also takes the shape of flow net into account (Saucke, 2006). The proposed critical gradients should be regarded with precaution, as they do not cover backward erosion and the exiting seepage would in these cases be directed upward, against the direction of gravity. Additionally, it was found that dams, which should be safe according to Bligh's and Lane's standards, have failed, whereas other structures which did not fulfil recommendations operated safely. A safe design based on these methods may therefore be questionable (Mansour, 2005). A further improvement of Bligh's and Lane's limit values was presented by Chugaev (Saucke, 2006), who paid closer attention to the actual flow net in his analysis of a large number of dams and weirs (Saucke, 2006). However, critical hydraulic gradients according to Chugaev are presented by Saucke (2006) and Mueller-Kirchenbauer et al. (1993) with slight variations: Limit values for coarse sand range from 0.25 to 0.33 , for medium sand 0.15 to 0.20 , and fine sand 0.12 to 0.16 . Obviously, Chugaev calculated a 'future factor', i.e. future development and improvement of knowledge, thus increased the critical gradients. Lower values include a safety factor and are therefore considered more reliable (Perzlmaier et al., 2007).

Table 1 Critical hydraulic gradients to initiate backward erosion and form a pipe (Perzlmaier et al., 2007)

\begin{tabular}{|c|}
\hline Borttaget: This e \\
\hline $\begin{array}{l}\text { Formaterat: } \\
\text { Teckensnitt:Kursiv }\end{array}$ \\
\hline $\begin{array}{l}\text { Formaterat: } \\
\text { Teckensnitt:Kursiv }\end{array}$ \\
\hline $\begin{array}{l}\text { Formaterat: } \\
\text { Teckensnitt:Kursiv }\end{array}$ \\
\hline $\begin{array}{l}\text { Formaterat: } \\
\text { Teckensnitt:Kursiv }\end{array}$ \\
\hline Borttaget: $_{\text {rit }}$ \\
\hline Borttaget: $_{r i t}$ \\
\hline $\begin{array}{l}\text { Formaterat: } \\
\text { Teckensnitt:Kursiv }\end{array}$ \\
\hline $\begin{array}{l}\text { Formaterat: } \\
\text { Teckensnitt:Kursiv }\end{array}$ \\
\hline $\begin{array}{l}\text { Formaterat: } \\
\text { Teckensnitt:Kursiv }\end{array}$ \\
\hline Borttaget: ${ }_{\text {rit }}$ \\
\hline
\end{tabular}

\begin{tabular}{|lllll}
\hline Type of soil & Gravel & Coarse sand & Medium sand & Fine sand \\
\hline$\underline{\mathrm{i}}_{\mathrm{c}}$ Chugaev & 0.25 & 0.25 & 0.11 & 0.10 \\
$\underline{\mathrm{i}}_{\mathrm{c}}$ Bligh & 0.11 & 0.083 & & 0.067 \\
$\underline{\mathrm{i}}_{\mathrm{c}}$ Lane & 0.095 & 0.067 & 0.056 & 0.048 \\
$\underline{\mathrm{i}}_{\mathrm{c}}$ Mueller-Kirchenbauer, lower limit & & 0.12 & 0.08 & 0.06 \\
$\underline{\mathrm{i}}_{\mathrm{c}}$ Mueller-Kirchenbauer, upper limit & & 0.17 & 0.10 & 0.08 \\
$\underline{\mathrm{i}}_{\mathrm{c}}$ Weijers and Sellmeijer, $\mathrm{C}_{\mathrm{u}}=1,5$ & 0.28 & 0.18 & 0.16 & 0.09 \\
$\underline{\mathrm{i}}_{\mathrm{c}}$ Weijers and Sellmeijer, $\mathrm{C}_{\mathrm{u}}=3$ & 0.34 & 0.28 & 0.24 & 0.14 \\
\hline
\end{tabular}


Mueller-Kirchenbauer carried out experimental studies on backward erosion, taking sub-surface layers and bedding conditions into account. Experimental results were verified by numerical studies and showed that critical hydraulic gradients presented by Chugaev could be applied in case of homogeneous sub-surface conditions, while they deviate for layered underground conditions (Mueller-Kirchenbauer et al., 1993). Weijers and Sellmeijer (1993) describe a method for calculation of the average critical gradient based on a mathematical description by means of a dikes' geometry, the difference in water head, length of a seepage path, as well as a certain seepage layer thickness are related to each other. In addition, the coefficient of uniformity $\mathrm{C}_{\mathrm{u}}$ is taken into account. The solution for calculation of a critical water head is verified by large scale tests, but is limited to geometry and material properties of specific sand found in the Netherlands.

Critical hydraulic gradients for internal erosion or suffusion have been experimentally studied by several authors, e.g. den Adel et al. (1988), Skempton and Brogan (1994), Tomlinson and Vaid (2000), and Richards and Reddy (2009).

In their laboratory tests, Skempton and Brogan (1994) noted a significant decrease in the critical gradient when dealing with internally unstable material. While the critical gradient was approximately 1 in internally stable materials and therefore consistent with Terzaghis theoretical value, unstable materials experienced material transport at lower values of $1 / 3$ to $1 / 5$ of those of stable materials (see Table 2). To explain the lower gradient, the stress conditions in an internally unstable material is considered and a reduction factor introduced, similar to that presented by Ziems (1969), see Equation (2). Skempton and Brogan compared their values to those presented by den Adel et al. (1988), who noted a gradient of 0.70 (i.e. lower than predicted by Terzaghis theory) for stable material, and 0.16 to 0.17 for unstable materials, see Table 2 . The higher values obtained by Skempton and Brogan may be due to the vertically upward directed flow, i.e. against gravity. In contrast, den Adel et al. (1988) carried out tests with horizontal flow direction.

Table 2 Experimental values of critical gradients for migration or piping in sandy gravels Skempton and Brogan, 1994)

\begin{tabular}{lll}
\hline Material & $\begin{array}{l}\text { Horizontal flow } \\
\text { den Adel et al., 1988 }\end{array}$ & $\begin{array}{l}\text { Vertical upward flow } \\
\text { Skempton and Brogan, } \\
\mathbf{1 9 9 4}\end{array}$ \\
\hline Unstable & $0.16-0.17$ & $0.20-0.30$ \\
Stable & 0.70 & 1.0 \\
\hline
\end{tabular}

Similar to Skempton and Brogan (1994), den Adel et al. (1988) related the critical hydraulic gradient to the internal stability of a material. Using the F-H method for analysis of internal instability presented by Kenney and Lau (1985), the grading curve of a soil material is divided into a mass fraction ' $F$ ' smaller than a particle size $\mathrm{D}$, and a mass fraction ' $\mathrm{H}$ ' between particle sizes $\mathrm{D}$ and $4 \mathrm{x} \mathrm{D}$. Mass fraction ' $\mathrm{F}$ ' then basically represents a base material, and mass fraction ' $\mathrm{H}$ ' a filter with a number of particles that form sufficiently small constrictions for filtration. A linear relationship between the grain size distribution of a material and a critical gradient could then be presented by den Adel et al. (1988). However, both den Adel et al. (1988) and Richards and Reddy (2009) emphasise that it is rather a critical velocity than a critical gradient which is important for the piping potential of a soil. Yet, it may be a more difficult property to determine, as the flow velocity in the pores is not constant and the critical velocity varies for each particle and its orientation.

Tomlinson and Vaid (2000) also regarded piping with respect to geometric criteria. A stable relation between filter and base soil particle distributions $\mathrm{d}_{15 \mathrm{f}} / \mathrm{d}_{85 \mathrm{~b}}<8$ is considered not to fail due to piping, while a grain size ratio of $\mathrm{d}_{15 f} / \mathrm{d}_{85 \mathrm{~b}}>12$ would fail. However, an intermediate grain size ratio of $8<\mathrm{d}_{15 f} / \mathrm{d}_{85 \mathrm{~b}}<12$ is expected to experience piping at a critical hydraulic gradient. The critical hydraulic gradient is defined as that at which piping develops, and the term 'disruptive gradient' is introduced. Vertically downward experiments with glass beads as filter layer for repeatability resulted in a critical gradient of 0,227 , which was found to be the 'onset of increase in gradient at which piping starts'. In addition, an unproportional increase of flow rate at the critical gradient was observed, which Tomlinson and Vaid related to variations in sample length. Assuming that Darcy's law is valid even in this test phase, with hydraulic conductivity and sample area constant, the flow rate changes are explained by the decreasing sample height due to eroding particles. 
Richards and Reddy (2009) consider the critical hydraulic velocity being the most important and reliable factor for piping in non-cohesive material. Both the critical hydraulic gradient and the corresponding hydraulic conductivity were found to vary irregularly during tests, whereas their product, i.e. the critical hydraulic velocity, was more consistent. An initial test series showed that the critical velocity ranged from 0.81 to $1.1 \mathrm{~cm} / \mathrm{s}$, at corresponding hydraulic gradients ranging from 0.13 to 0.24 . Evaluation of piping tests carried out at different seepage angle, i.e. in direction downward from a horizontal plane, showed that the critical velocity decreased. The direction of seepage, i.e. along with or against the direction of gravity, plays an important role for the erosion potential. The likelihood of erosion increases in downward direction with gravity, while it decreases in flow directed upward against gravity. To be able to apply results from laboratory tests on possible erosion in tailings dams, testing should therefore be carried out in similar direction as it occurs in reality, i.e. in downward direction.

\subsubsection{Current design practice for Swedish tailings dams}

Current design practice for Swedish tailings dams is related to basic soil mechanics and slope stability. The | safety factor for tailings dams slopes FS is assessed by means of the slope stability for infinite slopes, taking the internal angle of friction $\phi$, the angle of the slope $\beta$, and the effective density $\rho$ ' into account:

$$
F S=\frac{\rho^{\prime}}{1+\rho^{\prime}} \cdot \frac{\tan \phi^{\prime}}{\tan \beta}
$$

To determine a maximum slope angle, i.e. the slope of the phreatic surface, the tailings' friction angle $\phi$ ' is applied. This rule is, despite the lack of scientific verification, commonly accepted for the long term stability of tailings dams' slopes in Sweden. According to the Swedish dam safety guidelines RIDAS, the safety factor FS determined by limit state analysis being 1.5 is regarded being sufficient (Bjelkevik, 2005a). However, a major problem for this assessment is the determination of tailings' friction angle, as it can vary between $18^{\circ}$ up to $45^{\circ}$ (Jantzer et al., 2008). For a material with an internal angle of friction of $20^{\circ}$, a slope inclination of $7^{\circ}$ and a gradient of 0.12 could be accepted, whereas for a material with an internal angle of friction of $40^{\circ}$, a slope inclination of $15^{\circ}$ and a gradient of 0.27 would meet requirements for the safety factor.

Comparing gradients between $0.12-0.27$ in Swedish tailings dams to results from presented laboratory studies for internally unstable materials, it appears that the current guidelines allow gradients that lie within the range of what has been determined in various laboratory studies, i.e. between 0.13 (lowest result in studies by Richards and Reddy, 2009) and 0.30 (Skempton and Brogan, 1994). However, it should be remembered that laboratory results represent limit values where soil particle migration is initiated or migration has already taken place to a lesser degree. Thus, no safety factor would be taken into account in the design of tailings dams. This problem can become more significant when regarding the service life of a tailings dam and the materials' degradation over time. Upon degradation, particles will become more round and the internal angle of friction will be reduced, which would further decrease the critical gradient.

Results from empirical studies presented in Table 1 show that the critical hydraulic gradient for fine sand ranges between $0.048-0.14$. The critical gradients for fine sand are considered most relevant in this context, as both tailings and glacial till are relatively fine grained materials. Empirical studies thus show that the critical gradient can be lower in a water retaining structure compared to laboratory test results. Hence, current tailings dam design does not provide sufficient safety against piping and erosion.

\section{$3 \quad$ Natural analogies to dam constructions}

The design period for the physical stability of a tailings dam, e.g. slope stability, stability against erosion, or settlements, is normally regarded to be about 1,000 years in Sweden. Experience on such extended design periods is relatively limited. There are few examples on long term stable constructions that can be found in ancient structures, such as pyramids. Additional examples are e.g. stable slopes of man-made earthen mounds in China that have been stable over several thousands of years. These mounds were studied with respect to stable slope angles; their inclination varies from 16 to $28^{\circ}$. There are additional examples of manmade earth mounds, burial and entombment sites all over the world that are up to 6,000 years old (Bjelkevik, 2005a). The landscape in Scandinavia is characterised by numerous lakes as a result from an inland ice cover 
that was responsible for sedimentation and erosion. Geological formations which have and partly still fulfil the function of damming water have been examined by Agrell, Geological Survey of Sweden, SGU (2002). The study describes several examples of natural dammed lakes dated back to the last glaciation in Sweden about 15,000 to 8,000 years ago, showing that natural barriers are capable to operate effectively as a hydraulic barrier in long-time perspective. The location of examples of such natural dammed lakes, e.g. Lake Ragunda, Lake Hennan, Styggtjärn, Lake Mången, and Lake Skuttunge, is shown in Figure 3. In addition to these examples, Agrell states that there are an "infinite number of natural landforms similar to dam constructions" creating long-term stable hydraulic barriers, and that it is most probable that a barrier of soil can withstand aging and deterioration and retain water without experiencing significant erosion processes. Detailed information on examples can be found in Agrell (2002) or Jantzer (2009). Table 3 summarises basic information on selected examples based on Agrell (2002), including material and hydraulic gradient.

Table 3 Summary of natural analogies to dam constructions in Sweden (modified after Bjelkevik, 2005a)

\begin{tabular}{|c|c|c|c|c|}
\hline Place & $\begin{array}{l}\text { Difference in height } \\
\Delta \mathbf{h}[\mathrm{m}]\end{array}$ & $\begin{array}{l}\text { Distance } \\
\Delta \mathrm{l}[\mathrm{m}]\end{array}$ & $\begin{array}{l}\text { Hydraulic gradient } \\
\text { i }[\Delta \mathbf{h} / \Delta \mathbf{l}]\end{array}$ & Material \\
\hline Ragundasjö & 40 & 1000 & 0.04 & $\begin{array}{l}\text { glacial clay in layered } \\
\text { deposits of alluvium }\end{array}$ \\
\hline Hennan & 20 & 1000 & 0.02 & $\begin{array}{l}\text { glacial till over well } \\
\text { compacted sediments } \\
\text { from glacial stream from } \\
\text { earlier glaciation }\end{array}$ \\
\hline Mången & 16.5 & 1400 & 0.012 & $\begin{array}{l}\text { rubble, gravel, sand, fine- } \\
\text { sand and silty loam }\end{array}$ \\
\hline Styggtjärn & 2.1 & 100 & 0.021 & glacial till \\
\hline Skuttungesjö & 10 & 100 & 0.05 & not known \\
\hline Case study & 2.7 & 40.5 & 0.0675 & glacial till \\
\hline
\end{tabular}

The material in these natural formations is regarded being internally stable when considering the fact that they have been stable over thousands of years. Critical hydraulic gradients for internally stable soils measured in laboratory tests were set to $0.7-1.0$, see Table 2. Gradients in long term stable natural formations presented in Table 3 are between one to two orders of magnitude lower. This shows that gradients determined in laboratory conditions should be questioned, especially with respect to the long term performance of a material against erosion.

The laboratory value of critical hydraulic gradient is significantly decreased when regarding internally unstable materials and has been found to range between 0.13 and 0.30 (Richards and Reddy, 2009, Skempton and Brogan, 1994). Tailings may be regarded as internally unstable, as the material is often uniform and does not fulfil self-filtrating criteria suggested by Kenney and Lau (1985). Because tailings are often used in the actual dam construction, sufficient filter layers need to be provided, which could also be regarded being difficult due to the uniformity of tailings. Considering the comparatively lower values found in nature for internally stable soils, it is assumed that the limiting gradient for particle migration in long term constructions with unstable materials should be even lower.

\section{Conclusions}

The objective of this study was to contribute to tailings dams design with respect to critical hydraulic gradients. Information on critical hydraulic gradients given in literature was collected and long term stable natural formations were presented. Natural analogies to dam constructions are considered to give valuable information on the long term stability of tailings dams. These examples show that it is basically possible for an embankment to withstand a certain hydraulic gradient over long time periods; in this case since the last glaciation, i.e. thousands of years. From these studies, the following conclusions can be drawn: 
- Empirically derived critical gradients for fine sand given in the literature range from 0.048 to 0.14 .

- Laboratory tests of the critical hydraulic gradient differ for internally stable and internally unstable soil materials. Internally stable soils experience particle migration at a gradient between 0.7 and 1.0, while internally unstable materials are more susceptible to particle migration and display critical gradients between 0.16 and 0.30 .

- Values for critical gradients determined in laboratory conditions are difficult to handle due to the varying procedures and definitions of a critical gradient, i.e. whether the critical gradient describes a limit at which particles start to move or whether a certain amount of erosion occurs.

- The hydraulic gradients in natural formations presented on basis of the study conducted by SGU and a case study are between 0.02 and 0.07 . These formations are considered to comprise internally stable soil materials, because they have been stable and have fulfilled the function of damming water over thousands of years.

- The design criteria for Swedish tailings dams results in theoretic hydraulic gradients between 0.12 and 0.27 based on a friction angle ranging from 20 to $40^{\circ}$. It should be stressed that using a criteria of this type excludes the degradation of the material over time. The design should not be based upon properties obtained from laboratory testing of 'fresh' materials only. Upon degradation, the angularity of tailings is expected to decrease and the particles will become more round, thus reducing the internal angle of friction and the corresponding hydraulic gradient. With regard to both degradation and the comparison to gradients found in natural formations, the design criteria should be modified to reduce the currently allowed gradient.

\section{Acknowledgements}

The research presented in this paper was carried out as a part of Swedish Hydropower Centre - SVC. SVC has been established by the Swedish Energy Agency, Elforsk and Svenska Kraftnät together with Luleå University of Technology, The Royal Institute of Technology, Chalmers University of Technology and Uppsala University.

Participating hydro power companies are: Andritz Hydro Inepar Sweden, Andritz Waplans, E.ON Vattenkraft Sverige, Fortum Generation, Holmen Energi, Jämtkraft, Karlstads Energi, Linde Energi, Mälarenergi, Skellefteå Kraft, Sollefteåforsens, Statkraft Sverige, Statoil Lubricants, Sweco Infrastructure, Sweco Energuide, SveMin, Umeå Energi, Vattenfall Research and Development, Vattenfall Vattenkraft, VG Power and WSP.

\section{References}

den Adel, H., Bakker, K.J. and Klein Breteler, M. (1988) Internal Stability of Minestone, in Proceedings International Symposium on Modelling Soil-Water-Structure Interaction, International Association for Hydraulic Research (IAHR), Netherlands, Balkema, Rotterdam, pp. 225-231.

Agrell, H. (2002) Naturligt dämda sjöar - analogier av dammkonstruktioner, Uppdragsrapport för Svarliden Guld AB, Geological Survey of Sweden SGU, Uppsala, Sweden (in Swedish).

Bjelkevik, A. (2005a) Water Cover Closure Design for Tailings Dams, State of the Art Report, Research Report, Luleå University of Technology, Luleå, Sweden.

Bjelkevik, A. (2005b) Stability of Tailings Dams. Focus on Water Cover Closure, Licentiate Thesis, Luleå University of Technology, Luleå, Sweden. 2005:85.

Chapuis, R.P. (1992) Similarity of internal stability criteria for granular soils, Canadian Geotechnical Journal, Vol. 29, pp. $711-713$.

Davies, M.P. (2002) Tailings Impoundment Failures: Are Geotechnical Engineers Listening? Geotechnical News, September 2002, pp. 31-36.

Fannin, R.J. and Moffat, R. (2006) A large permeameter for study of internal stability in cohesionless soils, Geotechnical Testing Journal, Vol. 29, No. 4, pp. 273-279.

Fell, R., MacGregor, P., Stapledon, D. and Bell, G. (2005) Geotechnical Engineering of Dams, A.A. Balkema, Leiden.

Foster, M., Fell, R. and Spannagle, M. (2000) The statistics of embankment dam failures and accidents, Canadian Geotechnical Journal, Vol. 37, pp. 1000-1024.

Jantzer, I. (2009) Critical hydraulic gradients in tailings dams - Comparison to natural analogies, Licentiate thesis, Luleå University of Technology, Luleå, Sweden. 
Jantzer, I., Bjelkevik, A. and Pousette, K. (2008) Material properties of tailings from Swedish mines, Nordic Geotechnical Meeting NGM 15, Sandefjord, Norway, 3-6 September 2008, pp. 229-235.

Kenney, T.C. and Lau, D. (1985) Internal stability of granular filters, Canadian Geotechnical Journal, Vol. 22, pp. 215-225.

| Lafleur, J. (1984) Filter testing of broadly graded cohesionless tills, Canadian Geotechnical Journal, Vol. 21, pp. 634-643.

Lafleur, J., Mlynarek, J. and Rollin, A.L. (1989) Filtration of broadly graded cohesionless soils, Journal of Geotechnical Engineering, Vol. 115, No. 12, pp. 1747-1768.

Mansour, B.G.S. (2005) Investigations on Design and Rehabilitation Options for River Barrages with Special Respect to Piping, Doctoral Thesis, Mitteilungen des Instituts für Grundbau, Bodenmechanik und Energiewasserbau, Universität Hannover, Heft 62.

Mitchell, J.K. and Soga, K. (2005) Fundamentals of soil behaviour, John Wiley and Sons, Inc., Hoboken, New Jersey.

Mueller-Kirchenbauer, H., Rankl, M. and Schlötzer, C. (1993) Mechanism for regressive erosion beneath dams and barrages, in Proceedings Filters in geotechnical and hydraulic engineering, J. Brauns, M. Heibaum, and U. Schuler (eds), A.A. Balkema, Rotterdam, pp. 369-376.

Perzlmaier, S., Muckenthaler, P. and Koelewijn, A.R. (2007) Hydraulic Criteria for Internal Erosion in Cohesionless Soil, in Proceedings Assessment of the Risk of Internal Erosion of Water Retaining Structures: Dams, Dykes and Levees - Intermediate Report of the European Working Group of ICOLD, Contributions to the Symposium in Freising, Germany, September 2007.

Richards, K.S. and Reddy, K.R. (2009) True Triaxial Piping Test Apparatus for Evaluation of Piping Potential in Earth Structures, Geotechnical Testing Journal, Vol. 33, No. 1, pp. 83-95.

Saucke, U. (2006) Nachweis der Sicherheit gegen innere Erosion fuer Körnige Erdstoffe, Geotechnik 29, 2006 No. 1, pp. $43-54$

Sherard, J.L., Dunnigan, L.P. and Talbot, J.R. (1984) Basic properties of sand and gravel filters, Journal of Geotechnical Engineering, Vol. 110, No. 6, pp. 684-700.

Sherard, J.L., Steele, E.F., Decker, R.S. and Dunnigan, L.P. (1976) Pinhole Test for Identifying Dispersive Soils, Journal of the Soil Mechanics and Foundations Division, Vol. 102, No. 1, pp. 69-85.

Skempton, A.W. and Brogan, J.M. (1994) Experiments on piping in sandy gravels, Géotechnique, Vol. 44, No. 3, pp. $449-460$.

Terzaghi, K., Peck, R.B. and Mesri, G. (1996) Soil mechanics in engineering practice, Third Edition, John Wiley \& Sons Inc., New York.

Tomlinson, S.S. and Vaid, Y.P. (2000) Seepage forces and confining pressure effects on piping erosion, Canadian Geotechnical Journal, Vol. 37, pp. 1-13.

Wan, C.F. and Fell, R. (2004a) Investigation of Rate of Erosion of Soils in Embankment Dams, Journal of Geotechnical and Geoenvironmental Engineering, Vol. 130, No. 4, pp. 373-380.

Wan, C.F. and Fell, R. (2004b) Experimental investigation of internal instability of soils in embankment dams and their foundations, NICIV Report No. R429, University of South Wales, Sydney, Australia.

Weijers, J. and Sellmeijer, J. (1993) A new model to deal with the piping mechanism, in Proceedings Filters in geotechnical and hydraulic engineering, J. Brauns, M. Heibaum, and U. Schuler (eds), A.A. Balkema, Rotterdam, pp. 349-355.

Zhang, L.M. and Chen, Q. (2006) Seepage failure mechanism of the Gouhou rockfill dam during reservoir water infiltration, Soils and Foundations, Vol. 46, No. 5, pp. 557-568.

Ziems, J. (1969) Beitrag zur Kontakterosion nichtbindiger Erdstoffe, Doctoral Thesis at Technische Univeristät Dresden, Germany (In German).
Borttaget: Kenney, T.C., Lau, D. and Ofoegbu, G.I. (1984) Permeability of compacted granular materials, Canadian Geotechnical Journal, Vol. 21, pp. $726-729.9$ 